\title{
Performance Evaluation of Microfinance Providers Using Data Envelopment Analysis: The Profitability Perspective
}

\author{
Sadia Farooq *
}

\begin{abstract}
Maximizing profitability is an important prerequisite for dealing with rising competition in the microfinance industry and ensuring long term sustainability. While profitability measurement is more commonly based on ratio analysis technique; the current study uses a non-parametric linear programming tool, known as Data Envelopment Analysis (DEA) for this purpose. This study makes a contribution to the existing research on the profitability of microfinance providers (MFPs), by investigating the Pakistan-based operations of a set of MFPs. The results of the analysis reveal considerable potential for improvement in profit efficiency of a number of selected MFPs.
\end{abstract}

Keywords: Microfinance providers (MFPs), profitability, Data envelopment analysis (DEA)

\section{Introduction}

Microfinance providers (MFPs) ${ }^{1}$ are specialized institutions that are in the business of offering financial services to low income people and micro businesses that do not have access to other formal financial institutions (Tchuigoua, 2016). For lower income developing economies, the problem of financial exclusion of poor assumes great importance because more than $80 \%$ of people living in these economies are excluded from formal financial sector (Robinson, 2001).

In the initial stages of its development, the microfinance industry mainly comprised of non-governmental organizations (NGOs) that had a purely social mission of helping the poor. With the passage of time, however, commercially oriented organizations have also been lured to the field, mainly due to the high untapped potential, and in some cases due to government pressure (Bounouala \& Rihane, 2014). As a result, microfinance sector at present is comprised of both social and profit oriented organizations. The co-existence of such diverse business models is a proof of the resilience of this sector (Bos \& Millone, 2015).

At the same time, with the entrance of different types of profit-oriented commercial organizations, level of competition has scaled to new heights. In order to survive in such competitive environment, MFPs today are required to cover their costs and achieve con-

\footnotetext{
* Asst. Professor, Hailey College of Commerce, University of the Punjab. E-mail: sadia.hcc@pu.edu.pk

${ }^{1}$ The literature on microfinance normally refers to microfinance providers as microfinance institutions. However, considering the distinct categorization of the microfinance providers into MFBs, MFIs and RSPs in Pakistan, this study has used the umbrella term MFP to refer to any of the different sub categories of institutions involved in the business of offering microfinance services to the poor.
} 
siderable levels of financial sustainability (Hamada, 2010; Zeller \& Meyer, 2002). The current study thus analyzes the financial sustainability of a group of MFPs, and makes recommendations for improving performance of the MFPs having lower profitability levels (Ali, 2015).

\section{Literature Review}

Microfinance refers to a particular class of financial services that are targeted towards lower income people, with normal transaction sizes being usually small i.e. smaller than per capita GDP (Isern \& Porteous, 2005). Microfinance providers (MFPs), by the same definition, are specialized institutions that cater to the financing requirements of those poor people who are unable to access the services of the formal financial sector. The financial services offered through such institutions include small (micro) loans and deposits; as well as money transfer, payments and insurance services. Women, in particular, are a major target of most microfinance programmes, as they are considered to be more credit constrained as compared to their male counterparts (Khandker, 1998).

The concept of microcredits was initiated by Dr. Muhammad Yunus in 1970's, when the renowned economist challenged the widely held belief of poor being high credit risk entities by the formal financial institutions. Before the advent of the microfinance methodology and since the beginning of the evolution of the formal financial sector, there has been an inherent reluctance to lend to the poorer segments of the societies. Inability of the poor to provide adequate collateral is considered to be a main cause of such financial exclusion. In addition to the purportedly high risk of non-payment of the loaned amounts, higher transaction costs are another well-known deterrent to the access of formal sources of financing for the poor (Coleman, 2006). Yet another mitigating factor is the relatively larger costs involved in provision of finance to the poor clients, due to high transaction costs and smaller loan sizes (Fernando, 2006).

The aforementioned phenomenon of scarcity of financial services for the poor has been observed in both the developed and developing countries alike. The situation in the developing economies is especially worse as is evident by the observation that nearly, 1.7 billion adults in the developing economies do not have an account with any financial institutions (Demirguc-Kunt, Klapper, Singer, Ansar, \& Hess, 2018). This exclusion from the formal financial sector forces the financially deprived poor people to borrow from the informal sources such as relatives and acquaintances, which are scarce and unpredictable or the money lenders which tend to by excessively expensive (Siwar \& Talib, 2001).

The cost of availing financial services from MFPs is also considered to be relatively higher in comparison to similar loans offered by commercial financial institutions. According to a study by Rosenberg, Gonzalez, and Narain (2010), MFIs tend to charge an average interest rate of $26 \%$, which is quite high when compared to ordinary banks' interest rates. Interest rates for profit oriented MFIs are reported to be even higher. However, such costs are still considered affordable and accepted by the poor, because otherwise these people are forced to pay exorbitant prices for borrowing from informal sources of finance. As a result, there is lesser exploitation of the poor at the hands of money lenders and loan sharks that comprise major segment of informal financial market. In addition, by 
offering the resource constrained people employment opportunities and enhancing their economic participation, the goals of poverty reduction and improvement in quality of life can also be facilitated through micro financing.

In initial stages of development, the focus of microfinance strategy was solely on micro-credits with some of the institutions offering saving services as well. However, with the passage of time, the field of microfinance has evolved considerably; and now includes not only micro credits and savings, but also a host of other financial and non-financial services. A few examples of the non-financial services offered by MFPs include, but are not restricted to, skill up-gradation and entrepreneurship development of the clients (Sarkar \& Singh, 2006), safety nets and livelihood training (Ravi, 2008), compulsory participation in savings and social and financial education programmes (Dulal, Gingrich, \& Stough, 2008).

Since its inception in 1980s' the pace of developments in the microfinance field has been astronomical. The number and types of MFPs serving the poor has been increasing and so has the volume of the poor people being served by these institutions. However, at the same time, this flourishing industry is facing a number of challenges, among which rising competition is a prominent one. Due to the conversion of many socially oriented MFPs to profit making ones and the enhanced role of commercial organizations in the provision of micro finance services, the MFPs are faced with increasing competition. While a competitive environment can act as good incentive which can lead to greater efficiency and improved quality of services, it also imposes certain limitations. The increased competition has in particular placed a lot of pressure on all MFPs; whether originally profit oriented or not, to become financially sustainable (Assefa, Hermes, \& Meesters, 2013).

At present, the microfinance industry of Pakistan is comprised of a variety of MFPs including NGOs, specialized banks, rural support programmes and even some commercial financial institutions. In the microfinance industry of Pakistan, profitability risk has been recognized as the second biggest risk, surpassed only by the risk associated with the macroeconomic trends (Haq \& Khalid, 2011). The inability of MFPs to attain suitable levels of profitability can hinder not only their growth but also commercial viability of these institutions.

Considering the importance of being sustainable and profitable in current environment of enhanced competition, this study analyzes and compares the profitability of a number of MFPs with a view to offer suitable suggestions for overcoming any inefficiencies observed.

\section{The Selection of Appropriate Estimation Technique}

A review of the literature on performance evaluation of MFPs reveals that the academic community has used a number of statistical and mathematical techniques for evaluating different aspects of MFPs' performance. In this regard, various parametric and nonparametric techniques have been used. However, to date, ratio analysis remains one of the most commonly used technique for performance measurement, favored by the practitioners in the field of microfinance. 
The literature also identifies a number of reasons for inadequacy of ratio analysis as an analytical tool. A major reasons for not relying on ratio analysis as a tool for measuring performance efficiency of financial institutions is that it can focus on only two activity dimension through any one indicator (Smith, 1990). This limitation of the ratio analysis to account for the multi-dimensional production process leads to a failure to reflect, either the full scope of an institution's activities, or the complexities involved in its decision making processes (Athanassopoulos \& Ballantine, 1995). In addition, ratio analysis does not lend itself to the provision of a suitable definition and framework of efficiency analysis (Bolli \& Thi, 2012), fails to take into account the economies of scale considerations (Worthington, 1998), and lacks the ability to identify best practices and appropriate benchmarks for comparison purpose (Flückiger \& Vassiliev, 2007).

A good alternative to ratio analysis, for measuring and comparing performance of MFPs, is Data Envelopment Analysis (DEA). DEA is a non-parametric technique based on linear programming. This analytical tool is known for its ability to compare the performance of institutions that use similar inputs to produce similar outputs.

An important underlying concept for efficiency computation through DEA is Pareto optimality, according to which a firm will not be considered efficient unless it is not possible to increase any of its outputs without increasing some of its inputs or decreasing some other output/s. In a similar vein, Pareto efficiency will not be achieved by a firm if it can lower any of its inputs without a subsequent increase in any other input or without decreasing some output/s (Thanassoulis, 2003).

Of the two main DEA models, the first model was developed by Charnes, Cooper, and Rhodes (1979) and this model assumes constant returns to scale (CRS). The second model, as proposed by Banker, Charnes, and Cooper (1984) introduced the assumption of variable returns to scale (VRS). The resulting efficiency scores from a DEA analysis lie between 0 and 1 (or 0 and 100\%). As DEA focuses on relative performance and not on absolute performance, therefore, any firm scoring less than $100 \%$ is considered to be relatively inefficient. Such scoring helps compare the performance of observed units in the selected sample in relation to each other.

In addition to the identification of suitable benchmarks, DEA also offers approximations for potential improvements achievable by less efficient DMUs (Avkiran, 2001), thus making it a suitable tool for the this study. DMU is the abbreviation for "decision making unit" and is used to denote any firm or organization for which DEA analysis is being conducted.

\section{Methodology}

As discussed in the previous section, the current study proposes the use of Data Envelopment Analysis (DEA) for measuring and comparing the profit performance of selected MFPs. Through the proposed analysis, the technical profit efficiency is to be calculated in order to understand the effectiveness of the production process in converting the selected inputs into outputs. 


\section{The DEA Model Specification}

For optimal use of the DEA technique, a number of aspects for appropriate model specification need to be considered. A discussion of these aspects is provided herewith.

\section{The Core Profitability Model}

The study proposes the use of core profitability model which has been suggested by Avkiran (2011). This model uses a parsimonious set of variables to capture the profitability dimension of MFPs' performance, through calculating their technical efficiency scores.

\section{Variables for the Study}

There are two input variables under the selected profitability model including, the financial and operating expense. The two output variables are financial income and operating income. The selected variables have also been used in a number of previous studies (Avkiran \& Thoraneenitiyan, 2010; Leightner \& Lovell, 1998; Lozano-Vivas, Pastor, \& Pastor, 2002; Miller \& Noulas, 1996).

\begin{tabular}{|c|c|c|}
\hline Variable Name & Variable Type & Description \\
\hline Financial Expense & Input & $\begin{array}{l}\text { This variable is comprised of the interest, commissions and } \\
\text { fees paid on the total liabilities, including deposits of clients } \\
\text { and any other commercial or concessionary borrowings, } \\
\text { mortgages and facility fees against credit lines. }\end{array}$ \\
\hline Operating Expense & Input & $\begin{array}{l}\text { Operating expense includes both the administrative and personnel } \\
\text { expenses. Note that personnel expense variable consists of salaries, } \\
\text { benefits and bonuses for the staff, as well as recruitment and initial } \\
\text { orientation costs. However, it does not normally include the cost of } \\
\text { specialized or ongoing training costs of existing staff which is } \\
\text { considered to be an administrative expense. In addition, the } \\
\text { administrative expense is that which is incurred on financial and other } \\
\text { services provision to the clients. The examples of such expenses include; } \\
\text { rent, depreciation, advertising, supplies, utilities and } \\
\text { transportation and communication etc. }\end{array}$ \\
\hline Financial Income & Output & $\begin{array}{l}\text { This variable is represented by the income earned by an MFP from } \\
\text { its loan portfolio and other financial assets and includes; interest, } \\
\text { commissions and fees on gross loan portfolio as well as revenues } \\
\text { earned from dividends, interest and other payments from } \\
\text { financial assets, other than loan portfolio. }\end{array}$ \\
\hline Operating Income & Output & Operating income is the income earned through non-lending activities of an MFP. \\
\hline
\end{tabular}

This section (Table 1) offers an explanation of the selected variables in line with the guidelines provided by CGAP (2003) ${ }^{2}$.

\section{Testing for Appropriate Returns to Scale}

A major decision for DEA analysis relates to selection of appropriate returns to scale (RTS). The DEA models are generally run under assumption of either constant or variable

\footnotetext{
${ }^{2}$ All the variables are denominated in Pakistan Rupee (PKR, 000).
} 
returns to scale. Wrong assumption about RTS can lead to inaccuracy in efficiency scores so obtained which might be confounded due to presence of scale efficiencies. As proposed by Avkiran (2001), the core profitability model was run under both CRS and VRS assumptions to test the suitability of either assumption. The results showed considerable variation in efficiency scores under the two assumptions, thus suggesting appropriateness of VRS rather than CRS assumption for the selected data set. We, therefore, propose the use of variable returns to scale (VRS) for the current study.

\section{Orientation Selection}

The DEA models are generally run under either input or output orientation. The suitability of either orientation is context dependent. For the present study, the use of input orientation is preferred. This choice is based on the understanding that the management of MFPs may be in a better position to exercise control over the input variables as opposed to the selected output variables. The ability of management to exercise better control over input or output variables is considered to be an appropriate criterion for selection of DEA model orientation (Coelli, Rao, O’Donnell, \& Battese, 2005).

\section{Data and Sample Selection}

The sample for current study comprises of three main categories of MFPs. The first is microfinance banks (MFBs), the second is microfinance institutions (MFIs) and the third is rural support programmes (RSPs). The data is extracted from the audited financial reports corresponding to the year ending 2014, for those MFPs that are members of the Pakistan Microfinance Network (PMN). The original sample comprised of a total of 42 MFPs. Of the originally selected data set, four of the MFPs had to be dropped due to the presence of zero amounts for certain variables. Of these dropped MFPs, Akhuwat and Naymet were not included due to the absence of any financial expenses, while DEEP and BAIDRE could not be analyzed as these MFPs did not have any operating income. This means that final data set for the study comprises of 38 MFPs in total.

The selected sample is considered a good sized sample for a DEA analysis. According to a general rule of thumb, sample size should be larger than the product of total outputs and total inputs (Avkiran, 2001) or, alternately; it should be three times bigger than the total number of inputs and outputs combined (Nunamaker, 1985). The product of selected inputs and outputs for this study comes up to be 4 ( 2 input variables, multiplied by 2 output variables), while the sum of inputs and outputs multiplied by 3 comes up to be 12 . In both cases the actual sample size of 38 MFPs is much bigger than the minimum size requirement.

\section{Results and Discussion}

The results of the selected DEA model, obtained through Frontier Analyst Software (Table 2 ), reveal that there are a total of 12 MFPs which are found to be $100 \%$ efficient, under 
the core profitability model. This group of fully efficient MFPs includes; ASA-P, BEDF, GBTI, KBL, NRSP, POMFB, PRSP, SRDO, Sungi, TMFB, VDO, and WASEELA ${ }^{3}$. Taking into consideration the organizational structure; there are three MFBs, two RSPs and seven MFIs which comprise this group of MFPs with 100\% efficiency score. These 12 MFPs are thus the suitable reference points whose practices need to be emulated by the inefficient MFPs.

\begin{tabular}{lccc}
\multicolumn{4}{l}{$\begin{array}{l}\text { Table } 2 \\
\text { Results of Efficiency Analysis }\end{array}$} \\
\hline \multicolumn{1}{c}{ MFPs } & $\begin{array}{c}\text { Efficiency } \\
\text { Score } \%\end{array}$ & MFPs & $\begin{array}{c}\text { Efficiency } \\
\text { Score } \%\end{array}$ \\
\hline AMFB & 48.54 & OCT & 65.34 \\
AMRDO & 60.19 & OPD & 70.61 \\
ASA-P & 100.00 & ORIX & 67.45 \\
Agahe & 66.16 & POMFB & 100.00 \\
BEDF & 100.00 & PRSP & 100.00 \\
BRAC-P & 50.57 & RCDS & 68.33 \\
CSC & 55.20 & SAATH & 89.10 \\
DAMEN & 70.94 & SRDO & 100.00 \\
FFO & 50.75 & SRSO & 54.21 \\
FINCA & 59.46 & SRSP & 95.55 \\
FMFB & 75.99 & SSF & 50.92 \\
GBTI & 100.00 & SVDP & 53.80 \\
JWS & 53.04 & Sungi & 100.00 \\
KASHF & 94.50 & TMFB & 100.00 \\
KBL & 100.00 & TRDP & 75.64 \\
MO & 79.84 & U-Bank & 38.88 \\
Mojaz & 57.03 & VDO & 100.00 \\
NRSP & 100.00 & WASEELA & 100.00 \\
NRSP-B & 95.72 & Wasil & 55.18 \\
\hline
\end{tabular}

\section{Distribution of Efficiency Scores}

A look at the distribution of efficiency score (Figure 1) reveals that in addition to the twelve $100 \%$ efficient MFPs, there are three more MFPs which are having a high level of efficiency scores falling between 91 to $99 \%$. While a single MFI is falling between the efficiency range of 81 to $90 \%$. The second highest number of MFPs belongs to 51 to $60 \%$ efficiency score range. Of the remaining MFPs, 3 have efficiency rating of 71 to $80 \%$ and 6 MFPs fall between 61 to $70 \%$ efficiency score range.

Among the last five MFPs, efficiency scores of 4 institutions are between 41 to $50 \%$ and the poorest performer is having efficiency score falling between 30 to $40 \%$.

\footnotetext{
${ }^{3}$ The names of MFPs have been adopted as these appear in records of Pakistan Microfinance Network (PMN).
} 
Figure 1

Distribution of Efficiency Scores

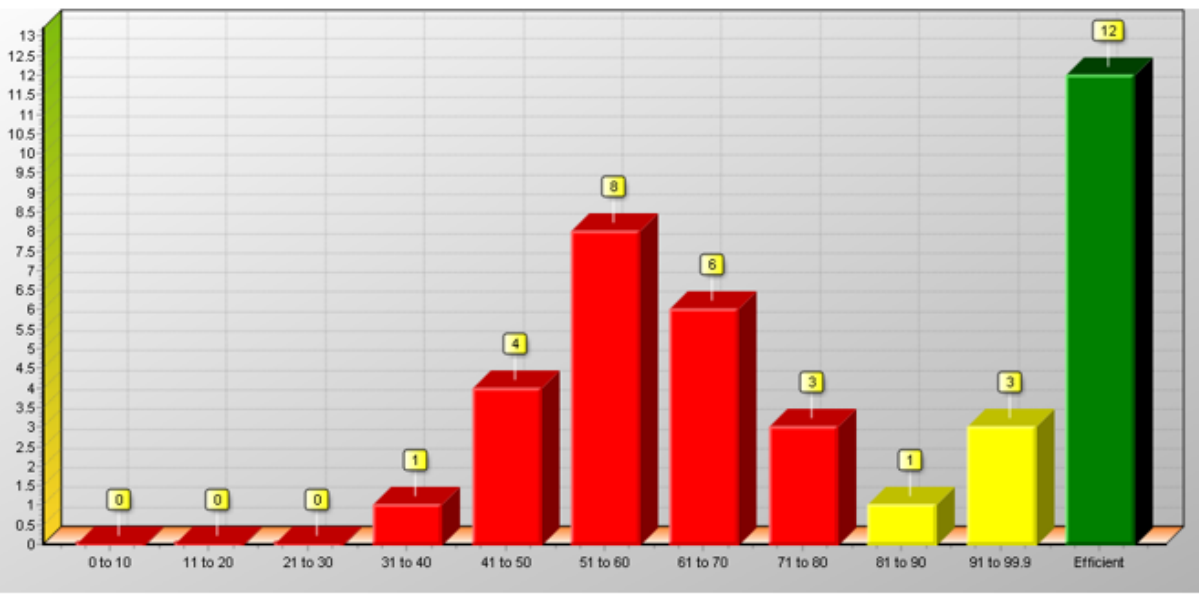

\section{Summary of Potential Improvements}

The pie-chart (Figure 2) summarizes the total potential improvement that the group of selected MFPs can attain if working at their full potential. The total potential improvement in financial interest expense for the selected MFPs is observed to be $20.88 \%$, while such improvement for operating expenses is $19.27 \%$. For the outputs on the other hand, there is only a nominal possible increase in financial income, while the scope for improvement in operating income is considerable at $58.57 \%$.

Figure 2

Total Potential Improvement for Selected Variables

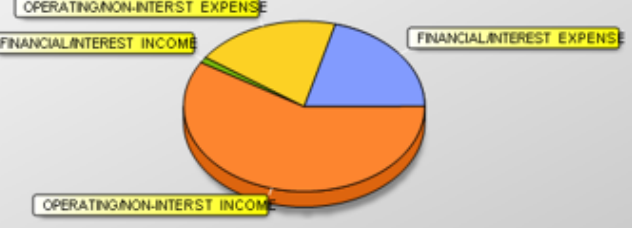




\section{Benchmarking}

As an analytical tool, DEA is known for its ability to facilitate benchmarking process for the DMUs being analyzed. Benchmarking is the procedure through which it is possible to identify appropriate measures for comparison of the performance standards achieved by similar organizations. Such comparison, in turn, can lead to achievement of superior levels of performance (Zhu, 2014). Figure 3 explains the frequency with which the high performing MFPs are appearing as a reference for other MFPs. For relatively inefficient MFPs, such efficient peers can act as benchmarks, whose best practices can be emulated for improving efficiency.

It can be seen from Figure 3 that PRSP, ASA-P, GBTI, WASEELA, Sungi and VDO are more frequently appearing as a reference for inefficient peers. In this regard, PRSP is the global leader as it appears as a reference for 20 MFPs. The second MFP is ASA-P, which appears as a reference for 17 MFPs. GBTI and WASEELA appear 15 times, Sungi 10 times and VDO appears 10 times as a reference MFP.

Figure 3

Frequency of High Scoring MFPs to Appear as Reference for Inefficient Peers

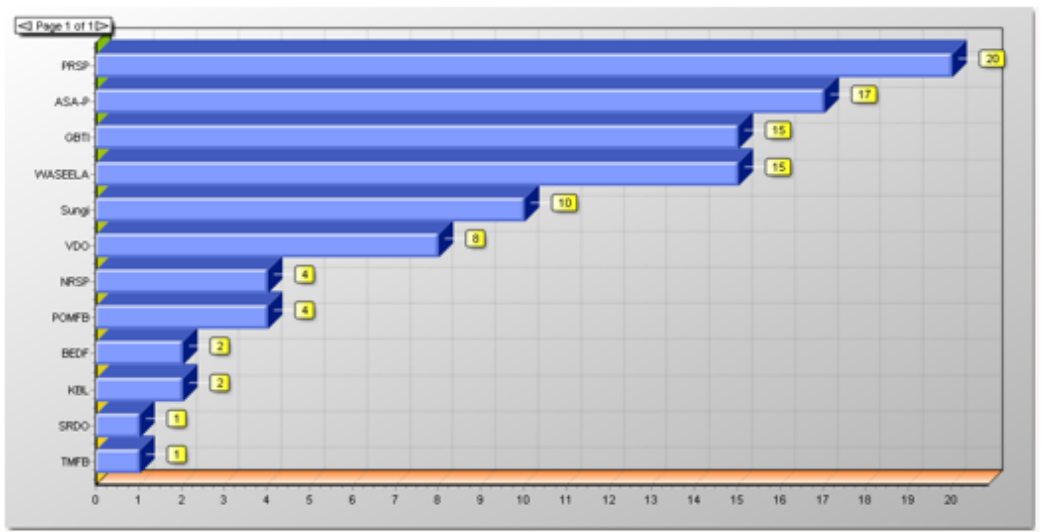

Further investigation of the scores of inefficient MFPs can help reveal the benchmark or target levels for different variables that these MFPs should try to achieve ${ }^{4}$. For example, U-BANK is the lowest scoring MFP, with an efficiency rating of 38.88\%. Its efficient peers include ASA-P, POMFB, Sungi, and WASEELA. Thus U-Bank can improve its efficiency by following the practices of these efficient peers. The results of the DEA model also reveal that cutting down both the financial and the operating expenses by approximately $61.12 \%$ is recommended for U-Bank.

Another low scorer in the list is AMFB with an efficiency score of $48.54 \%$, while its efficient reference peers are ASA-P, GBTI, PRSP, and WASEELA. This MFP needs to decrease its operating and financial expenses by $51 \%$, which may be achieved by following

\footnotetext{
${ }^{4}$ For brevity sake, the discussion is focused on MFPs with less than $70 \%$ profit efficiency scores. Further information can be provided on request.
} 
its efficient peers. BRAC-P has achieved efficiency score of $50.57 \%$, with a reference set including ASA-P, POMFB and WASEELA. The proposed reduction for its financial expense is $49.43 \%$, and for operating expense $54.80 \%$. FFO has scored $50.75 \%$ on profit efficiency and its efficient peers are ASA-P, GBTI, PRSP and WASEELA. By reducing its operating and financial expenses by $49.25 \%$, FFO can achieve desired level of profit efficiency.

SSF is another MFP which has achieved low efficiency score at 50.92\%. ASA-P, PRSP, and Sungi are its efficient peers and a reduction of $49.08 \%$ in its financial and operating expenses can be recommended. The next MFP named JWS has been able to achieve $53.04 \%$ profit efficiency. Its efficient peers are ASA-P, PRSP, and Sungi. For improving its profit efficiency, this MFP should try to decrease both the financial and operating expenses by $46.96 \%$. SVDP has scored $53.80 \%$ profit efficiency while the reference set for this MFP is comprised of GBTI, PRSP, VDO and WASEELA. SVDP should curtail both input expense variables by $46.21 \%$ for improving this efficiency score.

The next low scoring MFP is SRSO whose efficiency is found to be $54.21 \%$. There are four efficient peers whose practices it can emulate, namely; ASA-P, GBTI, PRSP, and WASEELA. A reduction of $45.79 \%$ is recommended for its operating and financial expenses for improving efficiency. Wasil, with an efficiency score of $55.18 \%$ is yet another low scoring MFP. The efficient peers for Wasil include; GBTI, PRSP, VDO, and WASEELA. The recommended reduction in the operating and financial expense for achieving higher profit efficiency is $44.82 \%$. CSC has relative efficiency score of $55.20 \%$. Its efficient peers include ASA-P, PRSP, and Sungi. In order to improve its profit efficiency, CSC needs to reduce its operating and financial expenses by 44.80

For Mojaz the relative profit efficiency score is $57.03 \%$ and its efficient peers include GBTI, PRSP, VDO and WASEELA. For improved efficiency score, $42.97 \%$ reduction in both the operating and financial expenses is desirable. The profit efficiency score for FINCA is $59.46 \%$. It has two efficient peers, namely; ASA-P and KBL. In order to improve ites efficiency score, FINCA needs to reduce its financial expenses by $40.54 \%$ and operating expenses by $40.67 \%$.

AMRDO, has scored $60.19 \%$ and has GBTI, PRSP and Sungi as efficient peers. The proposed reduction in its operating and financial expenses, according to the analysis conducted, is $39.81 \%$. OCT has three efficient peers namely; GBTI, PRSP and Sungi and its profit efficiency is $65.34 \%$. A reduction of $34.66 \%$ is recommended in financial and operating expenses of OCT, as a means of improving the efficiency score. For Agahe, the profit efficiency score is found to be $66.16 \%$. The efficient peers for this MFP are GBTI, PRSP, VDO and WASEELA. Agahe can improve its profit efficiency by cutting down its expenses by $33.84 \%$.

The profit efficiency score for the next institution ORIX is $67.45 \%$. There are four efficient peers for this MFP, namely; GBTI, ASA-P, PRSP and Sungi. ORIX should control and reduce its operating and financial expenses by $32.55 \%$ in order to achieve higher profit efficiency. And finally, the last MFP scoring less than $70 \%$ efficiency score in the current analysis is RCDS. RCDS has a profit efficiency score of $68.33 \%$ and it has three efficient peers including; ASA-P, PRSP, and Sungi. It needs to reduce its financial and operating expenses by $31.67 \%$ for performing better on the efficiency front. 


\section{Conclusion}

Enhancing profitability can be a major strategy to deal with competition and sustainability issues faced by MFPs today. This study has analyzed a group of MFPs from Pakistan, using DEA, which is a well-known operational research technique, and offered insight into how these institutions can improve profitability dimension of their performance. The results show that there are a number of MFPs with less than $70 \%$ relative efficiency scores thus suggesting considerable scope for improvement in profitability performance of these MFPs.

The results of the study can facilitate the benchmarking process and help various MFPs in highlighting their particular areas of strength and weaknesses, as compared to their more efficient peers. This, in turn, can be useful for formulating policies to overcome inefficiencies and build on inherent strengths.

\section{Future Research Directions}

This study has focused solely on the profitability aspect of MFPs' performance, as per major research objective of evaluating their ability to survive in a competitive environment. The social performance of these institutions is another important dimension, which could be of relevance; particularly in situations, where an overall review of performance is the major goal. It is suggested that future research be conducted by incorporating both the profit and social performance of microfinance providers to give a more holistic picture. 


\section{References}

Ali, M. (2015). Bank profitability and its determinants in Pakistan: A panel data analysis after financial crisis. Journal of Management Sciences, 1(1), 1-14.

Assefa, E., Hermes, N., \& Meesters, A. (2013). Competition and the performance of microfinance institutions. Applied Financial Economics, 23(9), 767-782.

Athanassopoulos, A. D., \& Ballantine, J. A. (1995). Ratio and frontier analysis for assessing corporate performance: Evidence from the grocery industry in the UK. Journal of the Operational Research Society, 46(4), 427-440.

Avkiran, N. K. (2001). Investigating technical and scale efficiencies of Australian universities through data envelopment analysis. Socio-Economic Planning Sciences, 35(1), 57-80.

Avkiran, N. K. (2011). Association of dea super-efficiency estimates with financial ratios: Investigating the case for Chinese banks. Omega, 39(3), 323-334.

Avkiran, N. K., \& Thoraneenitiyan, N. (2010). Purging data before productivity analysis. Journal of Business Research, 63(3), 294-302.

Banker, R. D., Charnes, A., \& Cooper, W. W. (1984). Some models for estimating technical and scale inefficiencies in data envelopment analysis. Management Science, 30(9), 1078-1092.

Bolli, T., \& Thi, A. V. (2012). On the estimation stability of efficiency and economies of scale in microfinance institutions. KOF Working Papers No. 296: Swiss Federal Institue of Technology, Zurich..

Bos, J. W. B., \& Millone, M. (2015). Practice what you preach: Microfinance business models and operational efficiency. World Development, 70, 28-42.

Bounouala, R., \& Rihane, C. (2014). Commercial banks in microfinance: Entry strategies and keys of success. Investment Management and Financial Innovations, 11(1), 146-156.

CGAP. (2003). Definitions of selected financial terms, ratios, and adjustments for microfinance microfinance consensus guidelines. Washington, DC: Consultative group to assist the poor/The World Bank Group.

Charnes, A., Cooper, W. W., \& Rhodes, E. (1979). Measuring the efficiency of decisionmaking units. European Journal of Operational Research, 3(4), 339-338.

Coelli, T. J., Rao, D. S. P., O'Donnell, C. J., \& Battese, G. E. (2005). An introduction to efficiency and productivity analysis. New York: Springer.

Coleman, B. E. (2006). Microfinance in Northeast Thailand: Who benefits and how much? World Development, 34(9), 1612-1638.

Demirguc-Kunt, A., Klapper, L., Singer, D., Ansar, S., \& Hess, J. (2018). The global findex database 2017: Measuring financial inclusion and the fintech revolution. The World Bank.

Dulal, H. B., Gingrich, C. D., \& Stough, R. R. (2008). Do microfinance programmes really serve the poor? Evidence from rural Southeast Nepal. Journal of South Asian Development, 3(2), 253-268.

Fernando, N. A. (2006). Understanding and dealing with high interest rates on microcredit: A note to policy makers in the Asia and Pacific region. Asian Development Bank, Philippines. 
Flückiger, Y., \& Vassiliev, A. (2007). Efficiency in microfinance institutions: An application of data envelopment analysis to MFIs in Peru. New York: Palgrave Macmillan.

Hamada, M. (2010). Commercialization of microfinance in Indonesia: The shortage of funds and the linkage program. The Developing Economies, 48(1), 156-176.

Haq, A., \& Khalid, Z. (2011). Risks to microfinance in Pakistan: Findings from a risk assessment survey: Islamabad: Pakistan Microfinance Network.

Isern, J., \& Porteous, D. (2005). Commercial banks and microfinance: Evolving models of success: CGAP, Focus Note No. 28.

Khandker, S. R. (1998). Micro-credit programme evaluation: A critical review. IDS Bulletin, 29(4), 11-20.

Leightner, J. E., \& Lovell, C. K. (1998). The impact of financial liberalization on the performance of thai banks. Journal of Economics and Business, 50(2), 115-131.

Lozano-Vivas, A., Pastor, J. T., \& Pastor, J. M. (2002). An efficiency comparison of European banking systems operating under different environmental conditions. Journal of Productivity Analysis, 18(1), 59-77.

Miller, S. M., \& Noulas, A. G. (1996). The technical efficiency of large bank production. Journal of Banking \& Finance, 20(3), 495-509.

Nunamaker, T. R. (1985). Using data envelopment analysis to measure the efficiency of non-profit organizations: A critical evaluation. Managerial and Decision Economics, 6(1), 50-58. doi: 10.1002/mde.4090060109

Ravi, S. (2008). Who are the ultra poor? descriptive statistics from baseline survey of SKS-UPP Indian school of business.

Robinson, M. S. (2001). The microfinance revolution: Sustainable finance for the poor. Washington, D.C.: The World Bank.

Rosenberg, R., Gonzalez, A., \& Narain, S. (2010). Tmoving beyond storytelling: Emerging research in microfinance. In T. Watkins, A. \& K. Hicks (Eds.), The new moneylenders: Are the poor being exploited by high microcredit interest rates? Contemporary Studies in Economic and Financial Analysis. Emerald Group Publishing Limited.

Sarkar, A., \& Singh, J. (2006). Savings-led micro-finance to bank the unbankables: Sharing of global experience. Global Business Review, 7(2), 271-295.

Siwar, C., \& Talib, B. A. (2001). Micro-finance capacity assessment for poverty alleviation: Outreach, viability and sustainability. Humanomics, 17(1), 116-133.

Smith, P. (1990). Data envelopment analysis applied to financial statements. Omega, 18(2), 131-138.

Tchuigoua, H. T. (2016). Buffer capital in microfinance institutions. Journal of Business Research, 69(9), 3523-3537.

Thanassoulis, E. (2003). Introduction to the theory and development of data envelopment analysis. Kluwer Academic Publishers.

Worthington, A. C. (1998). Efficiency in Australian building societies: An econometric cost function approach. Applied Financial Economics, 8(5), 459-467.

Zeller, M., \& Meyer, R. L. (2002). The triangle of microfinance: Financial sustainability, outreach, and impact. Intl Food Policy Res Inst.

Zhu, J. (2014). Quantitative models for performance evaluation and benchmarking:. New York: Springer. 